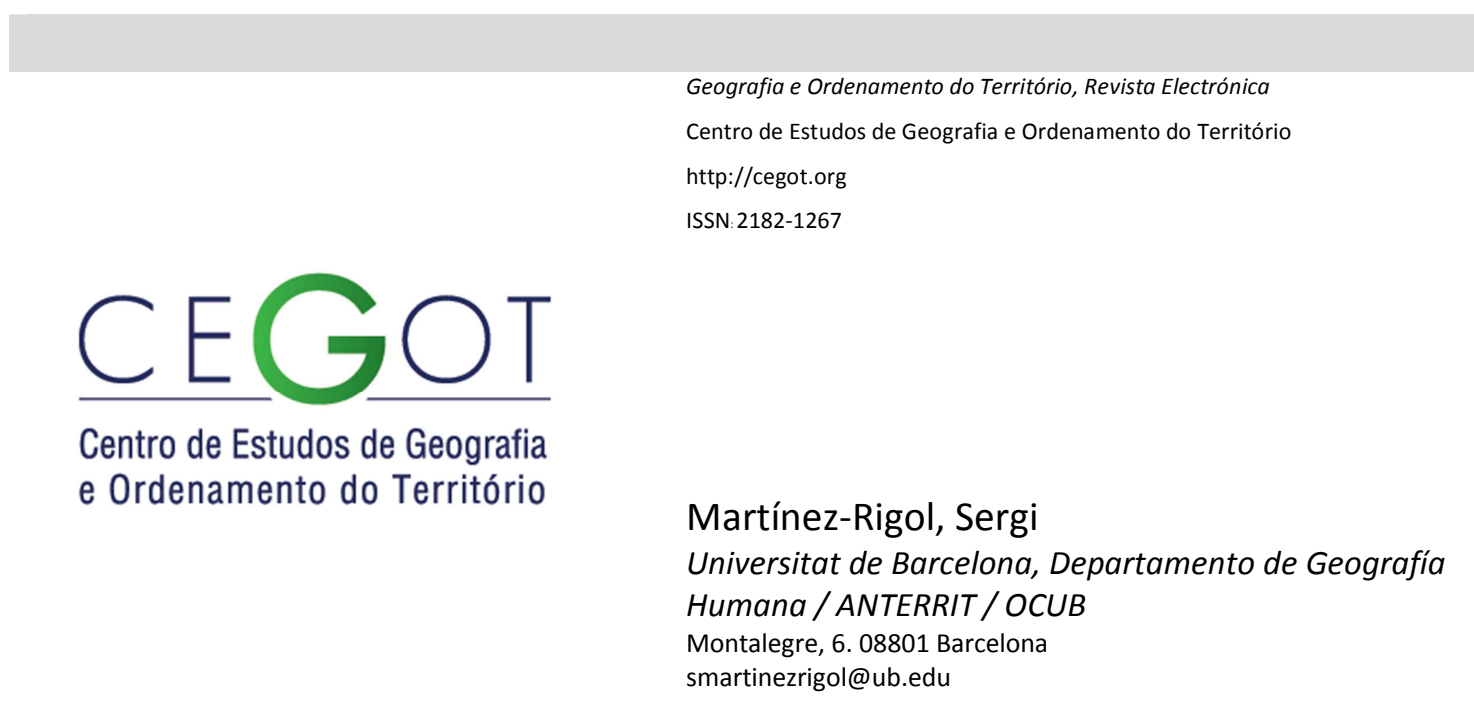

\title{
El Raval en crisis, la crisis del Raval ${ }^{1}$
}

Referência: Martínez-Rigol, Sergi (2015). El Raval en crisis, la crisis del Raval. (GOT), n.o 7 (junho). Centro de Estudos de Geografia e Ordenamento do Território, p. 231-250, dx.doi.org/10.17127/got/2015.7.010

\section{Resumen}

Hablar sobre la crisis del Raval es hacer referencia al hecho que, desde como mínimo la segunda mitad del siglo XIX, éste ha sido un barrio asociado constantemente a la crisis. Esta asociación ha significado la construcción, a través de diversos medios de comunicación o de textos, de una imagen y un discurso que han sobreexpuesto unas partes de la realidad del barrio, mientras que otras han sido escondidas, subexpuestas o ignoradas. Además, esta sobreexposición ha coincidido normalmente con la creación de una necesidad de intervención, sobre todo urbanística. Pero el proyecto urbano, basado en la intervención arquitectónica, intervención sobre la piedra, no ha cambiado las dinámicas sociales. Este ha sido, también, el gran fracaso en el Raval.

\section{Palabras clave:}

Crisis - Raval - Barcelona - discurso - agentes

1Una primera versión de este artículo fue presentada en el Seminario ANTERRIT 2013. Territorios ante la crisis. ¿Territorios en crisis? , celebrado en Barcelona del 16 al 18 de mayo de 2013, y organizado por el Grupo de Investigación Consolidado Anàlisi Territorial i Desenvolupament Regional (ANTERRIT, SGR2009-253) de la Universitat de Barcelona. Agradezco los comentarios que posteriormente y sobre el primer texto realizaron los colegas del Departamento de Geografía Humana de la Universitat de Barcelona Dr. Carles Carreras, Dr. Lluís Frago y Alejandro Morcuende, así como las aportaciones que han realizado los revisores anónimos. 


\section{Resumo}

Falar sobre a crise no Raval relaciona-se principalmente ao fato de que, pelo menos desde a segunda metade do século XIX, este tem sido um bairro constantemente associado ao conceito de crise. Esta associação tem significado a construção, através de diversos meios de comunicação ou de múltiplos textos literários, de uma imagem e um discurso que magnifica alguns contextos da realidade do bairro, enquanto outros foram escondidos, ignorados ou não foram suficientemente estudados. Além disso, esta exposição excessiva tem geralmente coincidido com a criação de uma necessidade de intervenção, especialmente no campo da planificação urbana. Contudo, o projeto urbano com base na arquitetura e na intervenção sobre os edifícios não mudou a dinâmica social. Este foi também o grande fiasco do Raval.

\section{Palavras-chave:}

Crise - Raval - Barcelona - fala - agentes

\section{Abstract}

Talking about the crisis in the Raval is referring to the fact that since at least the second half of the nineteenth century, this has been a neighborhood constantly associated with the crisis. This association has meant the construction, through various media or text, of an image and a discourse that have overexposed some portions of the reality of neighborhood, while others have been hidden, ignored or underexposed. Furthermore, this overexposure has typically coincided with the creation of a need for intervention, particularly from the urban point of view. But this urban project, based on an architectural intervention, an investment in stone, has not changed the social dynamics. This has been, also, the great failure in the Raval.

\section{Keywords:}

Crisis - Raval - Barcelona - discourse - agents

\section{Introducción. De la anécdota a la hipótesis.}

La presentación pública en el I Encuentro comunitario del Raval de la monografía La salud en el Raval. Una mirada desde el propio barrio (Fundació Tot Raval, 2013; Obra Social "la Caixa", 2013), dio pie a visualizar de nuevo el barrio del Raval en los titulares de los medios de comunicación escritos.

El encuentro, que tuvo lugar el 16 de abril de 2013 en el CIDOB (Barcelona Center for International Affairs, situado en la calle Elisabets, en el denominado cluster cultural del barrio del Raval), formaba parte de un proyecto de intervención comunitaria intercultural patrocinado por la Obra Social "la Caixa", promovido por la Fundació Tot Raval con la 
colaboración del Ayuntamiento de Barcelona, y que se encontraba enmarcado en el Pla de Barris del Raval Sud (2010-2018).

Cabe destacar la importancia del subtítulo de la monografía, en el que se ponía de relieve que la mirada partía desde dentro. Así, a pesar del carácter externo o interno respecto al Raval de las instituciones que impulsaron el proyecto de intervención comunitaria intercultural, y que han sido ya citadas, la participación en la monografía de más de un centenar de vecinos, de unos trecientos cincuenta profesionales y de unos cuarenta recursos culturales que de alguna forma están relacionados con la salud (Fundació Tot Raval; Obra Social "la Caixa”, 2013), aseguraron un cierto carácter interno, por lo que se consideraba que la mirada era desde dentro, desde el propio barrio. Tanto por el volumen de agentes implicados, por el hecho de pretender su coordinación, como por la voluntad de empoderamiento de la propia comunidad, este proyecto resultaba como mínimo, distinto a muchos de los proyectos de intervención urbanística o social llevados a cabo hasta el momento.

La presentación de la monografía tuvo resonancia en la prensa escrita. Así, buena parte de los periódicos nacionales hicieron referencia a ella, en El País se podía leer "El Raval tiene mala salud. La mortalidad entre los hombres es hasta un $43 \%$ más alta que en el resto de Barcelona" (Castedo, A., 2013). En el Periódico de Catalunya "La tasa de mortalidad de los vecinos del Raval es un $43 \%$ superior a la del resto de Barcelona. El $12 \%$ de niños y jóvenes del barrio sufre trastornos psicológicos y de personalidad" (El Periódico, 2103). En La Vanguardia el titular era "El Raval, a la cola de los indicadores de salud" (Sierra, LI., 2013). En el $A B C$, en su edición de Catalunya, el titular era "La esperanza de vida en el Raval es 5 años menor al resto de Barcelona. Un estudio analiza por primera vez las causas de enfermedad en este barrio degradado" (Leonelli, C., 2013).

También algunas revistas o periódicos de carácter electrónico, y quizás no tan generalistas, se hicieron eco del evento. Aquí, por ejemplo, se puede destacar Cáscara amarga, revista electrónica del colectivo LGTB, dónde se podía leer "El Raval, el barrio de Barcelona donde se concentra un gran foco de sida. Según un estudio la incidencia del VIH y el sida en este barrio es tres veces superior a la del resto de Barcelona" (Márquez, P., 2013). También el periódico Catalunya Religió destacaba en su titular que "El 12\% de los niños y jóvenes del Raval sufren trastornos psicológicos y de personalidad" (Catalunya Religió, 2013). 
Los titulares de los medios de comunicación no hicieron ninguna referencia a los aspectos menos sensacionalistas de la Monografía y del Encuentro. Aunque en los textos de las noticias sí que se podían encontrar referencias a la colaboración entre Administración, ciudadanía y profesionales o a la voluntad de empoderamiento de la comunidad, los titulares siempre fueron para aquellos aspectos más negativos que contribuyen a la recreación de un imaginario concreto sobre el barrio del Raval. De esta simple anécdota relacionada con un acto de presentación de una monografía, se puede pasar a la hipótesis que la crisis del Raval ha sido, y continua siendo, la sobreexposición o visualización de diversos problemas o cuestiones sociales, mientras que al mismo tiempo se han subexpuesto o se han ignorado otros elementos que conforman la realidad del barrio.

\section{Lo urbano y los medios de comunicación.}

El análisis de lo urbano a través de fuentes que podrían ser consideradas como no tradicionales no es una novedad. La Geografía ha superado, en un intento de comprensión de la ciudad, el uso de censos estadísticos de población, de propiedad o de actividades económicas, o de la cartografía topográfica o las imágenes aéreas y de satélite, y ha incorporado los textos literarios (Carreras, C., 2013²), la pintura (Zárate, A., 1992), el cine (Gamir, A. y Valdes, C.M., 2007; Martínez-Rigol, S., 2013a, 2013b), las series de televisión (Sommella, R., 2015) o la música (Panitz, L.M., 2012), entre otros, como fuentes de información privilegiadas.

El uso de estas fuentes es paralelo a la introducción de métodos y técnicas cualitativas que se dio a partir de la segunda mitad del siglo XX, como respuesta a la creciente preocupación en Geografía por investigar las motivaciones de los hechos socioespaciales, los significados, valores e interpretaciones de los lugares y de la vida cotidiana (García Ballesteros, A., 1998), y que se vio reforzado, ya a finales de siglo, por el denominado giro cultural, que a la postre ha significado la inclusión de variables culturales en los estudios urbanos, sobre todo con la

2 En su obra La ciudad en la literatura ofrece un excelente y extenso repaso sobre el uso que desde la Geografía se ha hecho de los textos literarios, tanto desde la Geografía española, como también desde una perspectiva internacional. 
denominada nueva geografía cultural (Cosgrove, D., 1990; Claval, P., 1995; Tuan, Y.-F., 2013).

En el marco del análisis de la cultura, y en especial de la cultura de masas, fundamentado en la teorización gramsciana de la ideología y la hegemonía cultural (Gramsci, A., 1966), así como también en las aportaciones de Raymond Williams desde la teoría literaria (Williams, R., 1977), y del denominado círculo de Birmingham, destaca el uso de los medios de comunicación, los media, como fuente de información para comprender lo urbano, y en especial, para comprender la percepción y la experiencia del espacio.

En este sentido, la prensa oficial difunde las ideas hegemónicas, como por ejemplo ya mostró Mike Davis sobre el caso del períodico Los Angeles Times y la ciudad californiana de Los Ángeles (Davis, M., 1992). Y es en este marco, en el que se se incluye el presente artículo, que pretende mostrar cómo, a partir del análisis de la prensa escrita, se construye un determinado discurso sobre el barrio del Raval, basado en la sobreexposición o subexposición de determinados temas, y que a la postre justifican determinadas intervenciones urbanísticas.

Se ha realizado una búsqueda de noticias relacionadas con el barrio del Raval entre los años 2008 y 2013 en las hemerotecas digitales de los períodicos La Vanguardia, El Periódico de Catalunya y El País, de las que a lo largo de este texto sólo se destacan algunas, y que se corresponde con el período de la crisis económica y social.

\section{De la crisis a la Crisis}

La crisis actual que acecha a la sociedad española, catalana, e incluso en mayor o menor medida a la de otros países europeos, sobre todo del sur o mediterráneos, e incluso de otros continentes, también ha dejado su huella en el barrio del Raval. La crisis actual, derivada de lo financiero y lo inmobiliario, caracterizada por el aumento del paro, la reducción de los salarios, los recortes en la administración pública, que han afectado profundamente al estado del bienestar, ha traído como consecuencia el aumento de los desahucios, el empobrecimiento de la población y una creciente dualización social. 
Estos efectos han sido si no más intensos, sí tan intensos en el Raval como en otros barrios de la ciudad de Barcelona. Con una población extranjera cercana al 50\%, unos índices de renta familiar inferiores a la media de la ciudad, un volumen de población envejecida y un volumen de población en riesgo de exclusión social o ya excluida socialmente considerables, han visto como los efectos de la crisis se cebaban sobre su situación ya de por si delicada.

Sin duda alguna, pues, el Raval, como otros barrios de muchas ciudades, está en crisis, y sus efectos son visibles a través de diversos indicadores de carácter estadístico o bien, también, a partir de la simple observación de la vida cotidiana del barrio, como por ejemplo el aumento de los indigentes presentes en los espacios públicos, o el aumento de población que acude a los comedores o servicios sociales que, sobre todo a través de diversas ONG, se ofrecen en el barrio ${ }^{3}$.

Pero esta crisis actual puede ser considerada como una estadio más en la Crisis en la que está inmerso el Raval desde, como mínimo, la segunda mitad del siglo XIX. Éste ha sido un barrio que constantemente se ha asociado a la crisis, de la que como se ha comentado anteriormente, se han sobreexpuesto en determinados momentos algunas características. Por ello, se debe tener una perspectiva temporal amplia, y contextualizar la crisis actual en una periodización en la que se pueden apreciar momentos de crisis que han justificado la intervención, sobre todo urbanística, en el Raval.

\section{El Raval y lo urbano: discursos y agentes.}

En el espacio urbano, en su conjunto, se dan unas formas y unos contenidos específicos, unos objetos concretos y unas acciones ligados a éstos. En cada uno de ellos se impone una

3 Un indicador de esta relación entre el Raval y la crisis se podría considerar, por ejemplo, la noticia aparecida con motivo del estreno de la película Biutiful (2010), del director Alejandro Gonzlez Iñárritu, parte de la cual tiene al Raval como escenario. El periodista Josep Playá, en el periódico La Vanguardia, ponía de relieve a raíz del estreno de la película, que muestra la cara menos amable de la ciudad de Barcelona, como la crisis había aumentado las desigualdades, y que con razón el Raval, dónde éstas eran más visibles, se había utilizado como plató. Sólo la actuación de muchas ONG estaban evitando que las consecuencias de la crisis fueran mucho peores (Playá, J., 2010). Como ya ha sido puesto de relieve, las relaciones entre ciudad y cine son complejas y fructíferas, y sin duda ayudan a explicar la producción de imágenes y la construcción de discursos de toda la ciudad o de sus partes (Martínez-Rigol, S., 2013a; 2013b). 
racionalidad concreta, algunas veces impuesta por vectores de fuerza externos, otras veces construida a partir de la solidaridad de los vectores internos. Fuerzas externas e internas que generalmente entran en conflicto, pues la imposición de normas externas tiene un efecto desintegrador de las solidaridades locales hasta entonces vigentes, con la pérdida correlativa de la capacidad de gestión de la vida local (Santos, M., 2000: 241).

\subsection{Interioridad y exterioridad}

Los vectores externos pretenden imponer una cierta racionalidad, es decir, unas formas y unos usos a los espacios para someterlos a sus intereses. Los vectores internos, sobre las mismas formas, ofrecen otros usos. Son pues, apropiaciones diversas de la misma materialidad física del espacio.

Así el Raval, cómo cualquier lugar, es definido constantemente a partir de las relaciones entre las verticalidades y las horizontalidades (Santos, M., 2000), factores externos e internos que redefinen en cada momento el lugar y lo posicionan en el sistema de lugares (Santos, M., 1986). Las verticalidades han apostado hasta ahora, en su mayor parte, y desde los años ochenta del siglo XX, por un barrio abierto a la ciudad y al mundo, a través de la producción de nuevos objetos que han redefinido el espacio y las relaciones. Esta acción externa ha sido paralela al intento de eliminación de algunas horizontalidades y sus objetos heredados, configurando un barrio totalmente desarraigado de su historia y de su génesis, erosionando su memoria.

\subsection{Los discursos}

Paralelamente a este proceso de construcción física de objetos, al proceso de urbanización, se ha dado la creación de unos discursos, de unas determinadas narrativas para explicar el barrio, su historia y sus cambios. Discursos que, también con carácter externo e interno, participan en el proceso de definición del lugar, y que han sido importantes bien para la creación de una determinada imagen, bien para justificar un determinado tipo de intervención. 
Estos discursos o narrativas que se han hecho sobre el Raval, como su misma construcción física, han tenido también una dosis importante de interioridad o exterioridad (Santos, M., 2000). Las menos han sido las narrativas elaboradas desde el interior del barrio, y las más numerosas aquellas realizadas desde el exterior. La producción de una determinada imagen a partir de la literatura ha sido ampliamente estudiada, sobre todo por lo que respecta a la creación de la imagen del Barrio Chino (McDonogh, G., 1986; Martínez-Rigol, S., 2000; 2009; Carreras, 2003). También el papel de la creación de una nueva imagen por parte de los nuevos residentes del barrio, en el proceso de gentrificación, ha sido analizado (MartínezRigol, S., 2000). Los discursos internos han tenido menor resonancia, y en general siempre han sido mediados por los individuos e instituciones que han analizado el Raval, como por ejemplo investigaciones (Subirats, J. y Rius, J., 2008; Horta, G., 2010) y tesis doctorales (Fernández, M., 2012), o bien exposiciones realizadas por las instituciones culturales presentes en el barrio (AA.VV., 1998; Zulián, C., 1999).

\subsection{Los agentes}

Los agentes que producen estos discursos son diversos. En el análisis que sobre el Casc Antic de Barcelona lleva a cabo la antropóloga Nadja Monet, ofrece algunas diferencias de estos discursos, sobre todo destacando el de los residentes y el institucionalizado (Monet, N., 2002).

Aquí, para analizar la construcción del discurso sobre la crisis contemporánea del Raval, y su uso, se utilizarán solamente los discursos creados por los medios de comunicación escritos (incluyendo periódicos, revistas de difusión cultural o turística, y en algunos casos incluso anuncios publicitarios), complementados en algunos casos por los discursos generados desde la academia (y transmitidos a partir de la publicación de libros y artículos de revistas científicos, fruto de la investigación) y la administración (a través de estudios y memorias). En general discursos elaborados desde la exterioridad, creadores de opinión pública, y que se han convertido en los dominantes.

Por su lado, los discursos que sobre el barrio tienen los propios residentes e incluso los visitantes, aquí no serán utilizados, aunque sí que lo han sido en otros estudios (MartínezRigol, S., 2000), como ya se ha comentado. 


\section{Una periodización de la crisis}

Es posible establecer una periodización de la construcción de la imagen del Raval, a partir de diferentes discursos, asociada constantemente a la crisis, con sus correspondientes respuestas desde lo urbanístico. Este "juego" de visibilizar problemas sociales y proponer respuestas, ya fue analizado como una de las condiciones para el proceso de gentrificación del barrio (Martínez-Rigol, S., 2000), y también lo expresan los antropólogos Gaspar Maza, Gary McDonogh y Joan J. Pujadas en un artículo sobre la participación ciudadana en el Raval, cuando apuntan que Des de fa més d'un segle el barri del Raval (i, sobretot, la part que constitueix l'anomenat popularment barri Xino) ha estat identificat per la premsa, $i$ també pels reformistes polítics $i$ socials, com una àrea amb problemes que requereixen intervenció. La problemàtica "visible" del barri ha variat segons l'època i els autors: els riscos generats per la prostitució i la misèria (Boatwright i Da Cal, 1984; McDonogh, 1987), els problemas derivats de la injustícia social i de salubritat, la població drogoaddicta (Romaní, 1992), o els fenòmens de la immigració i la marginació social (McDonogh, 1993; Maza, 1999). Les diferents veus d'alarma, des d'una òptica conservadora, liberal o d'esquerres, sempre han identificat el Raval com un lloc de profund desordre social (Maza, G., McDonogh, G. y Pujadas, J.J., 2002: 116) ${ }^{4}$.

Siguiendo este esquema, aquí se muestran tres momentos en los que se ha sobreexpuesto alguna de las problemáticas sociales, relacionándolas con las propuestas urbanísticas generadas, o con otros tipos de intervención, y también confrontándolas con una parte de la realidad contemporánea del barrio que es un contrapunto. Al mismo tiempo se destaca, en prácticamente todos los casos, la exterioridad de todos estos discursos y acciones.

4 Desde hace más de un siglo el barrio del Raval ( $y$, sobre todo, la parte que constituye el denominado popularmente como Barrio Chino), ha sido identificado por la prensa, y también por los reformistas políticos y sociales, como un área con problemas que requieren intervención. La problemática "visible" del barrio ha variado según la época y los autores: los riesgos generados por la prostitución y la miseria (Boatwrigth y Da Cal, 1984; McDonogh, 1987), los problemas derivados de la injusticia social y de salubridad, la población drogaadicta (Romaní, 1992), o los fenómenos de la inmigración y la marginación social (McDonogh, 1993; Maza, 1999). Las diferentes voces de alarma, desde una óptica conservadora, liberal o de izquierdas, siempre han identificado al Raval como un lugar de profundo desorden social. 


\subsection{Insalubridad y discursos higienistas}

El Proyecto de Reforma Interior y Ensanche de Barcelona que plateó el ingeniero Idelfons Cerdà en el año 1859, en base al estudio de las condiciones de la clase obrera en la Barcelona ${ }^{5}$ que había iniciado pocos años antes el derribo sus murallas, puede considerarse como el inicio de esta dialéctica, en el sentido que es quizás el primer momento en que el planeamiento urbano aparece como la solución a los problemas sociales. La densidad y la insalubridad generada por la instalación en el barrio del Raval, como mínimo desde mediados del siglo XVIII, de fábricas y residencias obreras, fue tomada como el argumento para proponer un proyecto de reforma basado en la apertura de nuevas vías y la destrucción de la trama urbana.

La degradación física de los espacios públicos y privados del barrio fueron a partir de este momento una constante. Por un lado, la propuesta de reforma interior de Cerdà, y las posteriores variantes que fueron apareciendo, no se llevaron a cabo. Por lo que una parte importante del Raval estuvo afectada por un proyecto urbanístico que, hasta casi entrado el siglo XXI, no se completó, con la obra emblemática de la apertura de la Rambla del Raval. Por otro lado, cabe señalar que en este proceso de degradación no sólo la planificación urbana tuvo un papel destacado. También la particular legislación sobre el alquiler de viviendas en España, la LAU de 1985, que tampoco motivaba la reinversión y el mantenimiento de las viviendas ni de los edificios, ni por parte de los propietarios, ni tampoco por parte de los inquilinos.

Actualmente, en los medios de comunicación, sobre todo en la prensa escrita, es recurrente encontrar noticias relacionadas con la insalubridad de las viviendas y las malas condiciones de vida de la población residente del Raval. Así, es habitual encontrar titulares como "Precintados 20 locales en el Raval que eran usados como viviendas ilegales" (El Periódico, 2011) o "Jóvenes y familias convierten en pisos zulos del Raval sin luz ni agua" (El Periódico, 
2012). Al mismo tiempo, la insalubridad continúa siendo objeto de planes y proyectos, así, es uno de los ejes de actuación del Pla de Barris del Raval Sud (2010-2018), plan de intervención integral de la denominada zona sur del barrio del Raval. Aunque cabe destacar que sus propuestas en este terreno se enfocan sobre todo a la reforma y rehabilitación de los espacios comunes de los edificios.

Al mismo tiempo, y como contrapunto a esta visión pesimista, la existencia de estas viviendas degradas convive con la de un parque de viviendas destinadas a uso turístico. Aquí cabe distinguir entre el alquiler de toda la vivienda, de forma legal (los denominados apartamentos de uso turístico), o bien el alquiler de toda la vivienda o de sólo algunas habitaciones que se realiza de forma más o menos alegal. También hay un conjunto de viviendas y locales ya rehabilitados y orientados a una nueva población y a nuevos negocios. Así, por ejemplo, uno de los anuncios de un apartamento turístico situado en la calle Riereta describe el apartamento y el barrio en general como:

Un diseñado soleado y espacioso apartamento en el corazón del barrio del Raval multicultural, beneficiándose de sol durante todo el día. Recientemente renovado al más alto nivel, este apartamento es un oasis de calma en medio del barrio con más vida de Barcelona. A medida que el plano no da a la calle, que es muy tranquila y pacífica durante todo el día. El apartamento está justo al lado de la Rambla del Raval de, el corazón del Raval - Barcelona vibrante barrio multicultural, lleno de bares, tiendas y restaurantes de todo tipo y presupuestos. A partir de los bares de tapas y tiendas de kebab-a Cal Isidre, frecuentada por el Rey de España, este barrio tiene algo para todo el mundo! - y la falta de baños públicos un asalto a las fosas nasales. Si usted es de mente abierta, o curioso acerca de la vida a nivel de la calle, entonces usted podrá disfrutar de la zona. No hay nunca un momento aburrido, y te garantizo que verás algo raro cada día

Tenga en cuenta que el Raval no es para todo el mundo - si es de disposición sensible, o se ofenden fácilmente, esto puede no ser el barrio para usted. El Raval, al igual que muchas partes de la ciudad vieja de Barcelona, puede ser abrumador (www.9flats.com/es/places/47105-apartamento-barcelona-el_raval) ${ }^{6}$.

6 Se ha transcrito el texto tal y como aparece en el anuncio. Los errores gramaticales deben ser, en la mayoría de casos, fruto de una traducción automática al castellano, pues el texto original debía estar en inglés. 
Mientras que en el censo de pisos turísticos del año 2010 en el Raval había poco más de 150 de estas características (BOPB, 2010), en el año 2013, a través de los portales de alquiler de pisos turísticos y habitaciones, en algunos de ellos el Raval era incluso el barrio con una mayor oferta.

Sería posible establecer las múltiples fronteras que se dibujan hoy en el barrio, entre un proceso de rehabilitación y renovación, y uno de degradación, que también puede ser la frontera de la gentrificación que definió el geógrafo Neil Smith (Smith, N., 1996). Una frontera que se mueve, avanza y retrocede, día a día, con momentos claramente de violencia y lucha urbana, como los casos de violencia inmobiliaria que se han dado (Taller contra la violencia inmobiliaria y urbanística, 2006), con momentos también de resistencia, aunque escasa, como lo fue a los procesos de expropiación, realojo y expulsión, a raíz de diversas intervenciones urbanísticas fruto, sobre todo, de la apertura de la Rambla del Raval.

\subsection{Prostitución y delincuencia, y el mito del Chino.}

A principios del siglo XX fue cuando se bautizó al Raval como el Barrio Chino. Concretamente era el área más próxima al puerto, en la que se concentraron gran cantidad de actividades ligadas al ocio nocturno, como salas de baile y concierto, los cafès-concert ${ }^{7}$ y los cabarets, incluso con una cierta proyección internacional, tan bien descritos, por ejemplo, por el periodista Josep Maria Planes (Planes, J.M., 1931). También tuvo la peculiaridad de atraer a escritores, periodistas, artistas y bohemios, que fueron los que crearon y difundieron a través de sus obras la imagen y el mito del Chino (McDonogh, G., 1986; Villar, P., 1996; Martínez-Rigol, S. 2000, 2008).

Paralelamente, actividades ligadas a la prostitución y la delincuencia también tuvieron su asentamiento en este barrio. Los mueblés, los clubs y la prostitución en la calle, formaron parte también del paisaje urbano, creando una imagen más ligada a los bajos fondos, una imagen claramente pesimista. El proceso de deslocalización industrial, que llevó a las fábricas hacia el Ensanche u otras áreas de Barcelona o próximas, dejó un espacio vacío que

7 Cafés-concierto. 
fue ocupado por talleres, pero también por burdeles, clubs, casas de dormir, cabarets u otras actividades.

Toda esta mezcla tuvo su punto álgido durante los primeros años del siglo XX, cuando la neutralidad española durante la primera Guerra Mundial convirtió a Barcelona en un punto estratégico para el abastecimiento de los países beligerantes, produciendo una llegada de personas y capitales importante, en paralelo a un aumento de contrabando y la posibilidad de hacer dinero en muy poco tiempo. También la Exposición Universal de 1929 fue un momento de creación de riqueza, y de llegada de inmigración.

Una de las respuestas a la existencia, real o mítica, de estos bajos fondos, un área peligrosa con la concentración de crímenes, prostitución, contrabando, tráfico de drogas, sordidez o malas condiciones de vida, fue el Pla de Sanejament del Casc Antic ${ }^{8}$, en el marco del Plan Macià elaborado por el GATCPAC en los años treinta. Mientras que hasta este momento, los planes propuestos para la reforma de la ciudad histórica pasaban por el sventramento y la apertura de grandes vías de circulación (Plan Cerdà, 1859; Plan Baixeras, 1879; Plan Jaussley, 1905; Plan Darder, 1918; Plan Vilaseca, 1932), el del GATCPAC, inspirado por Le Corbusier y elaborado por Josep Maria Sert, pasaba por el esponjamiento, con el derribo de las viviendas malsanas, como el método para mejorar las condiciones de vida de la población residente y acabar con la existencia de los bajos fondos. Pero en general, los objetivos del plan era aquellos expresados por Lluís Companys, quien sobre el Raval dijo a Josep Maria Sert, podeu creure'm; si pogués ho enderrocaria a canonades ${ }^{9}$.

Hoy se da todavía una pervivencia y sobreexposición de las imágenes ligadas a los bajos fondos. Así, el tema de los pederastas ha sido uno de los que más relevancia mediática ha tenido, como por ejemplo con el descubrimiento de un supuesto caso de pederastía y pornografía infantil en el año 1997, que dio lugar a la publicación de artículos periodísticos como "La policía descubre en Barcelona una red de pederastas que deja pequeño el caso Arny" (Marchena, D., 1997). Como en muchos otros ejemplos, aunque inicialmente hubo detenciones e ingreso en prisión de algunos de los supuestamente implicados, finalmente el caso quedó en nada. La combinación de intereses políticos, urbanísticos y personales de

8 Plan de Saneamiento del Casco Viejo.

9 Podéis creerme, si pudiera lo derribaría a cañonazos. 
algunos de los personajes que se vieron implicados, además de la facilidad de invención por parte de los periodistas por el hecho que este caso se diera en el Raval, transformaron un pequeño grano de arena en una montaña. A modo de denuncia, el caso fue llevado a la literatura por el periodista Arcadi Espada, con el libro Raval, del amor a los niños (Espada, A., 2000), y que posteriormente fue plasmado en la gran pantalla por Joaquim Jordà en el año 2003, con la película De nens.

Los casos de redadas contra la prostitución, los proxenetas, o también casos de violencia, son también todavía motivo de titular en los periódicos. El barrio ha estado ligado continuamente a estas consideraciones sociales ${ }^{10}$. Así, en el año 2006 ya se anunciaba un “Golpe a la prostitución" (Figueredo, E., 2006), con la detención de 110 personas relacionadas con el comercio sexual en el marco de la operación denominada Constanza, y otras treinta personas eran detenidas en otra redada en el año 2008 (La Vanguardia, 2008). En estos últimos años, además, la prostitución ha estado claramente ligada a la inmigración, como otros problemas sociales, e incluso el terrorismo islamista.

Como contrapunto a esta difusión de la concentración de prostitución y delincuencia, de la pervivencia de los bajos fondos, también se da una utilización de éstos, de la sordidez, como atractivo del barrio para los turistas y visitantes. Esto es perfectamente visible en alguno de los locales de ocio del barrio, que recuperan este punto de sordidez pero adaptado a la modernidad $^{11}$, recuperan el barrio Chino que fue aniquilado casi por completo por la piqueta, y que hoy subsiste sólo en la memoria de algunos, en los libros, e incluso en el nombre de algunas plazas del barrio que recuerdan sobre todo a los literatos franceses que dieron fama internacional al Barrio Chino de Barcelona. Ello permite la construcción de un barrio cool o hipster, como se desprende de las últimas guías turísticas o reportajes sobre el Raval publicados en revistas:

Lleno de contrastes, tremendamente seductor, quizá chocante y cosmopolita hasta decir basta. El Raval es uno de esos rincones difíciles de describir. Hoy no es el oscuro enclave que dibujó Joan Colom con su cámara a mediados del siglo XX, sino ese lugar apasionante que

10 Cabe señalar, en este sentido, el libro publicado por Camilo José Cela en 1964, Izas, rabizas y colipoterras. Drama con acompañamiento de cachondeo y dolor de corazón, con fotografías de Joan Colom.

11 En este sentido puede verse, por ejemplo, la descripción de uno de estos locales que realiza la revista Time Out (Time Out, 2012). 
inmortalizaron películas como Vicky Cristina Barcelona (Woody Allen, 2008) o L'auberge espagnol (Cédric Klapisch, 2002). Poco se parece al barrio chino por el que deambulaba el detective Pepe Carvalho de Vázquez Montalbán, y mucho menos al ambiente Makinavaja del pasado siglo.

Decir hoy Raval es decir cultura, estilo alternativo, tendencia. Pero no es negativo mirar atrás: Salvador (sic) Genet subsistió mendigando en las calles de lo que llamaba "territorio moral" -como cuenta Juan Goytisolo en Genet en el Raval (Galaxia Gutemberg, 2009)-, en los locales del Raval triunfó la cupletista Raquel Meller, en este barrio fue tiroteado el anarquista Salvador Seguí por la patronal de principios del siglo XX, y hasta el ejército musulmán de Almanzor saqueó sus calles (Remesal, J., 2010).

En el mismo sentido, también es posible analizar el doble discurso que se elabora sobre la inmigración. Por un lado, como se ha visto, a la nueva inmigración se la relaciona, con la prostitución o la delincuencia, mientras que por otro lado la multiculturalidad es un valor positivo que se utiliza para la "venta" del barrio a nuevos residentes y visitantes.

\subsection{Miseria y drogas.}

La sobreexposición de los temas relacionados con la pobreza y la miseria de los residentes, así como las cuestiones relacionadas con el consumo y el tráfico de drogas, también han sido otro de los ejes sobre los que se ha construido la imagen del Raval, y por lo tanto, sobre los que se ha fundamentado también la necesidad de la reforma urbanística.

A mediados de los años ochenta, en la Barcelona preolímpica, surgió la movilización en el distrito de Ciutat Vella Aquí hi ha gana (Aquí hay hambre), que ponía de relieve los problemas de marginación y pobreza de este distrito de la ciudad, y también del Raval. Esto puso en primera página una realidad que existía, y todavía existe en el barrio, y que sin duda la crisis económica actual ha profundizado. Así, no es de extrañar la presencia importante que tienen en el Raval las instituciones, del tercer y cuarto sector, que se dedican a la asistencia a personas en riesgo o en situación de exclusión social.

El tráfico y el consumo de drogas también ha sido una constante en los titulares de los periódicos. En este sentido, cabe destacar que a mediados de los años setenta empieza un periodo caracterizado por la aparición de la heroína, aunque su presencia en el barrio es ya 
relatada por Llorenç Villalonga, en su obra Mort de dama, publicada en el año 1931. Ésta conllevó la aparición de clanes, sobre todo extranjeros, que intentaron controlar el tráfico con un alto grado de violencia y conflictividad. También la aparición de los yonquis, que dado el poder adictivo de esta droga, estarán relacionados con la delincuencia y la prostitución. La situación de marginación y delincuencia creció de forma alarmante, con claras conexiones con el proceso de expulsión social como mostró Pere López para los barrios de Santa Caterina y el Portal Nou (López, P., 1989), y siendo a la vez un argumento de mucho peso para el control social (Romaní, O., 1983) y la reforma.

Estos problemas de miseria y tráfico de drogas, claramente sociales, fueron, junto a la insalubridad de las viviendas analizada en el primer subapartado, las condiciones que motivaron el proceso de rehabilitación y reforma urbana que desde los años ochenta está en marcha, inicialmente bajo la figura urbanística del Plan Especial de Reforma Interior (PERI). También el plan de derribos e higienización de Ciutat Vella, en el momento que la ciudad se preparaba para los Juegos Olímpicos, dirigido por el entonces responsable del distrito, y posteriormente alcalde de Barcelona, Joan Clos, que terminó con numerosas pensiones y hostales, lugar de residencia de la población flotante. E incluso hoy ha motivado el Plan de Usos de Ciutat Vella, aprobado en el año 2013 por el Ayuntamiento de Barcelona, que prohíbe la instalación de más asociaciones dedicadas a la asistencia a personas en riesgo de exclusión social, con el objetivo de evitar su concentración.

Pero aún hoy aparecen titulares como "Dos detenidos con 150 gramos de 'shabú' y 4.000 euros en el Raval” (El Periódico, 2013a), "La 'farmacia' del barrio del Raval” (El Periódico, 2013b), "Más problemas con las drogas en el Raval" (Flotats, A., 2009), o "Una redada en el barrio barcelonés del Raval se salda con cuatro detenidos, 40 identificados y 2,7 kilos de hachís incautados" (La Vanguardia, 2007), entre muchos otros.

Y esta presencia de problemas con el tráfico y el consumo de drogas, así como con la miseria, pervive con locales que mantienen el recuerdo del consumo de sustancias alucinógenas, como la absenta y el paradigmático Bar Marsella, hoy propiedad municipal, que juntamente con otros en el Raval, forman la ruta de la absenta. 


\section{Conclusiones}

De lo anterior puede concluirse, en primer lugar, que hablar hoy de la crisis del Raval es hacer referencia, además de a los efectos de la crisis económica ya comentados, también a la pervivencia y sobreexposición de las imágenes ligadas a los bajos fondos, la inmigración, la marginación social, las drogas y la insalubridad del barrio. La crisis del Raval no es sólo el momento puntual del ahora, es el haber estado continuamente ligado a estas consideraciones sociales.

En segundo lugar, se ha destacado como estos problemas, sobreexpuestos o visualizados convenientemente en determinados momentos de su historia reciente, han sido los que han justificado determinadas operaciones urbanísticas. En este sentido, una primera aproximación nos muestra como buena parte de las narrativas creadas para la exposición de estos problemas, bien sea a través de la prensa, bien sea a través de otros medios o soportes, como la literatura, son de carácter externo al barrio, y sirven en última instancia, a los vectores externos que introducen nuevas racionalidades al territorio. Así, por ejemplo, estas operaciones urbanísticas debidamente justificadas han permitido una extracción de rentas urbanas, y cabe esperar que en un futuro no muy lejano, una vez superada la crisis, la sobreexposición de estos problemas volverá a ser la excusa para una nueva ronda de inversión de capital y de extracción de rentas. Otra invasión de capital (cabe recordar que el Raval es una área central de la ciudad), quizás está vez más ligado al turismo (se ha empezado por abrir la veda a la instalación de nuevos hoteles).

Y en tercer lugar, podemos constatar que esta es una crisis del modelo de planeamiento urbano. Los problemas sociales detectados y sobre los que se han fundamentado las actuaciones urbanísticas no han desaparecido. Nótese que a raíz de apertura de la Filmoteca de Catalunya en el año 2013, la última de las instituciones culturales que se ha instalado en el Raval, se ponía de relieve, también a través de la prensa, la persistencia de los problemas sociales (Angulo, S. y Benvenuty, L., 2013), agudizados por la crisis derivada de lo financiero y lo inmobiliario. Lo que sin duda está en crisis es la concepción del urbanismo basado en la inversión en piedra. $\mathrm{Y}$ esta es la idea que ha guiado el planeamiento urbano desde su concepción como ciencia social. 


\section{Bibliografía}

AA.VV. (1998): La ciutat de les paraules. Edicions de l'Eixample, Barcelona.

BOPB (2010): “Anunci de rectificació. Ajuntament de Barcelona, Districte de Ciutat Vella”, a Butlletí Oficial de la Província de Barcelona. 25 de noviembre de 2010. Pp. 1-10.

Carreras, C. (2013): La ciudad en la literature. Un análisis geográfico de la literatura urbana. Lleida, Milenio.

Claval, P. (1995): La Géographie culturelle. Paris, Nathan.

Cosgrove, D. (1990): “... Then we take Berlin: cultural geography 1989-90”, en Progress in Human Geography (14). Pp. 560-568.

Espada, A. (2000): Raval, de l'amor als nens. Anagrama/Empúries, Barcelona.

Fernández, M. (2012): Matar al "Chino". Entre la revolución urbanística y el asedio urbano en el barrio del Raval de Barcelona. Tesis de doctorado. Departamento de Antropología Cultural y Historia de América y África, Universitat de Barcelona.

HORTA, G. (2010). Rambla del Raval de Barcelona: de apropiaciones viandantes y procesos sociales. Mataró, El Viejo Topo.

GÁMIR, A. y VALDÉS, C.M. (2007): “Cine y Geografía: espacio geográfico, paisaje y territorio en las producciones cinematográficas", en Bolentín de la AGE, n. 45. Pp. 157-190.

GARCÍA BALLESTEROS, A. (coord.) (1998): Métodos y técnicas cualitativas en geografia social. Vilassar de Mar, Oikos-Tau.

GRAMSCI, A. (1966): Quaderni del carcere. Milano, Einaudi.

MAGRINYÀ, F. (2009): “El Ensanche y la Reforma de Idelfons Cerdà como instrumento urbanístico de referencia en la modernización urbana de Barcelona", en Scripta Nova. Vol XIII, n. 296 (3), 1 de agosto de 2009. Universitat de Barcelona. [http://www.ub.edu/geocrit/sn/sn-296/sn-296-3.htm].

MARTÍNEZ-RIGOL, S. (2000): El retorn al centre de la ciutat. El Raval entre la gentrificació i la reestructuració. Tesis de doctorado microfichada. Publicaciones de la Universitat de Barcelona, Barcelona.

MARTÍNEZ-RIGOL, S. (2009): “La construcció literaria del Barri Xino”, en Carreras, C. y Moreno, S. (eds.): Llegint pedres, escrivint ciutats. Pagès Editors, Lleida.

MARTÍNEZ-RIGOL, S. (2013a): "Ciudades de cine, el caso de Barcelona. Un buen ejemplo de industria creativa", en Biblio 3W. Revista Bibliográfica de Geografia y Ciencias Sociales. Vol. XVIII, no 1037, 15 de agosto de 2013. [http://www.ub.edu/geocrit/b3w-1037.htm]

MARTínEZ-RIGOL, S. (2013b): “Barcelona, city of celluloide”, en Cirelli, C. (ed.): Percorsi creativi di turismo urbano. Patron, Bologna. Pp. 879-889.

MAZA, G., MCDONOGH, G. W., \& PUJADAS, J. J. (2002). Barcelona, ciutat oberta: transformacions urbanes, participacio ciutadana i cultures de control al barri del Raval. Revista d'etnologia de Catalunya, 21. Pàgs. 114131.

MCDONOGH, G. (1986): El "Barri Chino": Un estudi de la geografia comparativa de la imaginació. Documento fotocopiado.

PANITZ, L.M. (2012): "Geografia e música: uma introdução ao tema", em Biblio 3W. Revista Bibliográfica de Geografia y Ciencias Sociales. Vol. XVII, no 978, 30 de mayo de 2012. [http://www.ub.edu/geocrit/b3w978.htm].

PLANAS, Josep Maria (1931): Les nits de Barcelona. Llibreria Catalonia, Barcelona [reeditado por la editorial Proa en 2001]. 
ROMANÍ, O. (1983): A tumba abierta. Autobiografía de un grifota. Anagrama, Barcelona.

SANTOS, M. (1986): “Espacio y método”, en Geocrítica. Cuadernos críticos de Geografía Humana. Año XII, no 65. Barcelona, Universitat de Barcelona.

SANTOS, M. (2000): La naturaleza del espacio. Barcelona, Ariel.

SMITH, N. (1996): The new urban frontier. Gentrification and the revanchist city. Routledge, London y New York.

SOMMELLA R. (2015), "Mad Men. New York tra splendore e crisi”, a Amato, F. y dell'Agnese, E. (ed.) Schermi americani. Geografia e geopolitica degli Stati Uniti nelle serie televisive. Unicopli, Milano. Pp. 205-217.

SUBIRATS, J. y RIUS, J. (2008): Del Xino al Raval. Hacer Editorial, Barcelona.

Taller contra la violencia inmobiliaria y urbanística (2006): El cielo está enladrillado. Entre el mobbing y la violencia inmobiliaria y urbanística. Ediciones Bellaterra, Barcelona.

TUAN, Y.-F. (2013): Romantic Geography: In Search of the Sublime Landscape. Madison, University of Wisconsin Press.

WILLIAMS, R. (1977): Marxism and Literature. London and New York, Oxford University Press.

ZÁRATE, A. (1992): “Pintura de paisaje e imagen de España: un instrumento de análisis geográfico”, en Espacio, Tiempo y Forma, Serie VI, Geografía. Pp. 41-66.

ZULIÁN, C. (dir.) (1999): Escenes escenas del Raval. Ajuntament de Barcelona y Centre de Cultura Contemporània de Barcelona, Barcelona.

\section{$\underline{\text { Artículos de prensa citados }}$}

ANGULO, S. y BENVENUTY, L. (2013): "Los problemas del Raval se enquistan pese a las reformas urbanísticas", $\begin{array}{llllll}\text { en } & L a & \text { Vanguardia. } & 28 & \text { de } & \text { diciembre }\end{array}$ [http://www.lavanguardia.com/vida/20121228/54356672144/problemas-raval-enquistan-pese-reformasurbanisticas.html]

CASTEDO, A. (2013): "El Raval tiene mala salud", en El País. 16 de abril de 2013. [http://ccaa.elpais.com/ccaa/2013/04/16/catalunya/1366099449_298682.html]

CATALUNYA RELIGIÓ (2013): “El 12\% de los niños y jóvenes del Raval sufren trastornos psicológicos y de personalidad", en Catalunya Religió, 16 de abril de 2013. [http://catalunyareligio.cat/es/articles/39519]

EL PERIÓDICO (2013): "La tasa de mortalidad de los vecinos del Raval es un 43\% superior a la del resto de Barcelona”, en El Periódico. 15 de abril de 2013. [http://www.elperiodico.com/es/noticias/barcelona/tasamortalidad-vecinos-raval-superior-resto-barcelona-2363993]

EL PERIÓDICO (2011): "Precintados 20 locales en el Raval que eran usados como viviendas ilegales", en EI Periódico, 28 de febrero de 2011. [http://www.elperiodico.com/es/noticias/sociedad/20110228/precintadoslocales-raval-que-eran-usados-como-viviendas-ilegales/904938.shtml]

EL PERIÓDICO (2012): “Jóvenes y famílias convierten en pisos zulos del Raval sin luz ni agua”, en El Periódico, 22 de setembre de 2012. [http://www.elperiodico.com/es/noticias/barcelona/20100922/vivir-metroscuadrados-sin-cocina-lavabo/491617.shtml]

EL PERIÓDICO (2013a): “Dos detenidos con 150 gramos de 'shabú' y 4.000 euros en el Raval”, en El Periódico, 14 de marzo de 2013. [http://www.elperiodico.com/es/noticias/barcelona/dos-detenidos-150-gramos-shabu4000-euros-raval-2340324]

EL PERIÓDICO (2013b): “La 'farmacia' del barrio del Raval”, en El Periódico, 8 de mayo de 2013. [http://www.elperiodico.com/es/noticias/barcelona/farmacia-del-barrio-del-raval-2384988]

FLOTATS, A. (2009): “Más problemas con las drogas en el Raval”, en El País, 8 de octubre de 2009. [http://elpais.com/elpais/2009/10/08/actualidad/1254989839_850215.html] 
FUNDACIÓ TOT RAVAL (2013): "I Trobada Comunitària sobre la salut al Raval: una mirada des del propi barri". Nota de prensa. [http://www.totraval.org/noticia/104/i-trobada-comunitaria-sobre-la-salut-al-raval-unamirada-des-del-propi-barri]

LA VANGUARDIA (2008): "La redada contra el proxenetismo en el Raval finaliza con una treintena de detenidos", en La Vanguardia, 7 de octubre de 2008. [http://www.lavanguardia.com/sucesos/20081007/53554973525/la-redada-contra-el-proxenetismo-en-elraval-finaliza-con-una-treintena-detenidos.html]

LA VANGUARDIA (2007): “Una redada en el barrio barcelonés del Raval se salda con cuatro detenidos, 40 identificados y 2,7 kilos de hachís incautados", en La Vanguardia. [http://www.lavanguardia.mobi/slowdevice/noticia/51300769351/Una-redada-en-el-barrio-barcelones-delRaval-se-salda-con-cuatro-detenidos-40-identificados-y-2-7-ki.html\#temas].

LEONELLI, C. (2013): "La esperanza de vida en el Raval es 5 años menor al resto de Barcelona”, en $A B C .22$ de abril de 2013. [http://www.abc.es/local-cataluna/20130422/abci-esperanza-vida-raval-anos201304191741.html]

MARCHENA, D. (1997): "La policía descubre en Barcelona una red de pederastas que deja pequeño el caso Arny", en La Vanguardia, 29 de julio 1997. [http://hemeroteca.lavanguardia.com/previewPdf.html?id=34636232\&search=EL\%20CASO\%2ORAVAL]

MÁRQUEZ, P. (2013): “El Raval, el barrio de Barcelona donde se concentra un gran foco de sida”, en Cáscara amarga, 20 de abril de 2013. [http://www.cascaraamarga.es/politica-lgtb/Igtb-espana/5072-el-raval-el-barriode-barcelona-donde-se-concentra-un-gran-foco-de-sida.html]

OBRA SOCIAL “LA CAIXA" (2013): "Profesionales, ciudadanía y Administración aportan su mirada sobre la salud en el barrio del Raval". Nota de prensa. [http://prensa.lacaixa.es/obrasocial/monografia-raval-proyectointervencion-comunitaria-intercultural-obra-social-la-caixa-esp_816-c-18020_.html]

REMESAL, J. (2010): "El Raval. El último barrio cool”, en Azul Marino. Revista de Cruceros de Transmediterránea. Pp. 42-55.

SIERRA, LL. (2013): "El Raval, a la cola de los indicadores de salud”, en La Vanguardia. 16 de abril de 2013. [http://www.lavanguardia.com/20130416/54371241215/el-raval-a-la-cola-de-los-indicadores-de-salud-Iluissierra.html]

TIME OUT (2012): “Madame Jasmine”, 28 de junio de 2012. [http://www.timeout.cat/barcelona/ca/musicanit/madame-jasmine]. 